\title{
Systemic analysis of the caulking assembly process
}

\author{
Claudiu Rodean ${ }^{1^{*}}$, Livia Dana Beju $^{2}$, and Paul Dan Brindasu ${ }^{2}$ \\ ${ }^{1}$ Continental Automotive Systems SRL, 8 Salzburg Street, Sibiu, Romania \\ ${ }^{2}$ Lucian Blaga University of Sibiu, Faculty of Engineering, 4 Emil Cioran Street, Sibiu, Romania
}

\begin{abstract}
The present paper highlights the importance of a caulking process which is nowadays less studied in comparison with the growing of its usage in the automotive industry. Due to the fact that the caulking operation is used in domains with high importance such as shock absorbers and brake systems there comes the demand of this paper to detail the parameters which characterize the process, viewed as input data and output data, and the requirements asked for the final product. The paper presents the actual measurement methods used for analysis the performance of the caulking assembly. All this parameters leads to an analysis algorithm of performance established for the caulking process which it is used later in the paper for an experimental research. The study is a basis from which it will be able to go to further researches in order to optimize the following processing.
\end{abstract}

\section{Introduction}

Nowadays technologies require fast and efficient processing which ensure high quality and low costs in addition with the process safety. Among the operations that ensure these needs it's included the caulking process. Caulking operation is an advanced process used to obtain permanent assemblies in various fields such as: automotive, aeronautics, medical or energy.



Fig. 1. Presentation of the caulking area.

\footnotetext{
* Corresponding author: claudiu rod90@yahoo.com
} 
Caulking is the deformation operation which consists of tightening press of a piece of material around another to avoid their relative movement (Fig 1). Part 2 is placed on Part 1 and a caulking tool strikes Part 1 in order to deform an amount of material in such a way, that the resulting assembly becomes non-removable.

Examples of domains where the caulking process is used are the brake systems (Fig. 2) and the shock absorbers (Fig. 3).

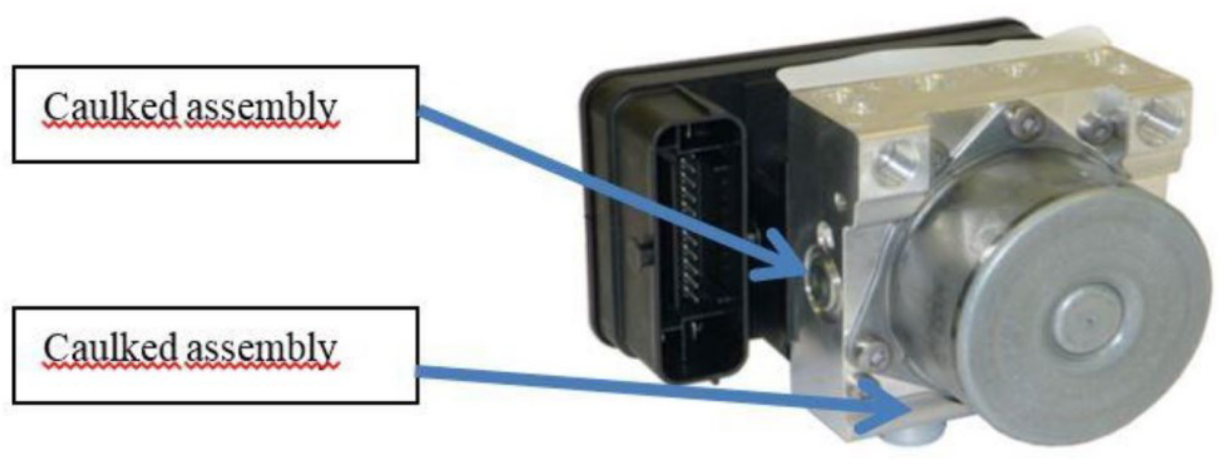

Fig. 2. Caulked assembly used at brake systems

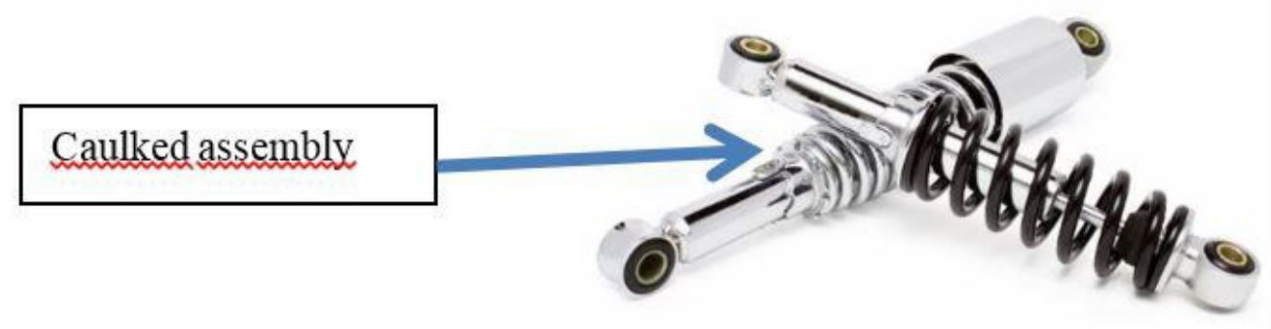

Fig. 3. Caulked assembly used at shock absorbers systems

In the automotive industry there are certain products that require special plastic deformation. In this area is framed the caulking operation which is started to be used on a larger scale operation because of the advantages it presents:

- The operation can be performed on CNC equipment.

- No material loss occurs.

- Replaces more complex operations, which have a higher cost.

- Operation allows the obtaining of accurate geometrical parameters of the assembly.

- The simulation using finite element method allows the optimisation of the process.

- It is a low cost operation.

Although at present, the caulking process begins to be used more and more, the technical literature do not analyze this process very much.

Sin and Lee [1] evaluated qualitatively a caulking through numerical analysis and inspecting a plastically deformed shape. Following the caulking analysis, the structural responses were considered. In addition, three design variables related to the manufacturing process were defined, and the effects of design variables with respect to pull-out strength, caulking depth, and maximum stress were obtained. Finally, the optimum design maximizing the pull-out strength was suggested. 
Park [2] studied an inner tie-rod (ITR) end-assembly module which is widely used in the steering systems of automobiles. The ITR module is composed of a ball-stud, ball-seat, and socket and manufactured by a caulking process. To ensure that the final ITR module is qualified for application, the caulking process of the ITR module was optimized to satisfy certain requirements, including the allowable displacement, pull-out force, tilting angle, and torque of the ball-stud. Accordingly, this paper investigates the deformation characteristics of both the caulking and pull-out processes using a finite element method analysis and clarifies the effect of the forming parameters on the allowable displacement, pull-out force, and tilting angle. The finite element method analysis results are also compared with experiments to validate the finite element method analysis.

Beck [3] study the heating tubes from the pressurized water reactor. The tightness is tested for the repaired tubes done using a roll-expanded plug.

Calcaletty [4] makes an analysis of the metrological leak detection method based on the application of mass spectrometry with tracer gas (generally helium).

Gorash [5] presents a numerical study involving the deformation of contact faces in the metal-to-metal seal in a typical pressure relief valve. The study method is the fluid pressure penetration technique.

An ideal caulking assembly must fulfil the following requirements:

- Precise geometrical parameters and high surface quality of the deformed volume of material.

- An adequate stress state along the entire caulking length.

- The assembling must have very good tightness.

- Assembly must withstand to fatigue.

- Low cost of the operation.

During a caulking assembly process, several problems may occur:

- The assembly does not acquire the imposed geometrical parameters.

- Sealing cracks appear along the caulking zone.

An assembly process can have several reasons which can cause these problems:

- The caulking force is out of range.

- The active area of the caulking tool is damaged.

- The device which holds the units is damaged.

- The press machine which drives the caulking tool can be damaged also etc.

The paper proposes to develop a method for the study of the performances of caulking assemblies by considering the entire caulking process as an Input-Output data system.

\section{Caulking operation viewed as a system}

Caulking process is a typical one which has input data such as geometrical and technological parameters and output data like geometrical parameters after caulking and values to be measured (Fig. 4).

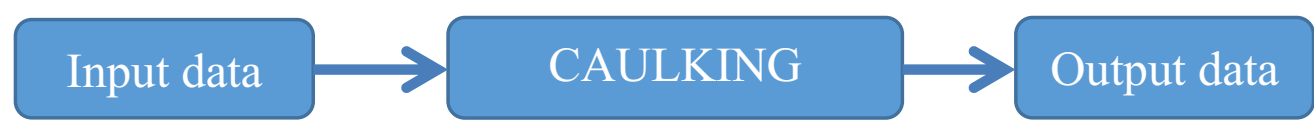

Fig. 4. Caulking operation - systemic perspective 
Due to the fact that there is a big list of requirements which it is asked by different customers, we intend to establish a list of technological demands which the caulking process must respect:

- Continuous deformation along the entire profile.

- Relative position between the parts and the caulking tool.

- Tool geometry.

- Caulking force.

In order to have a better understanding of the caulking process, a picture with all the geometrical parameters (before the caulking deformation process) is presented in figure 5.



Fig. 5. Geometrical parameters of the caulking process (before deformation)

The geometrical parameters of the two parts, defined before the caulking process is done (the "Input data") are:

- $\mathrm{H}$ - the height of the material which is deformed during the caulking process.

- ØDp 1 - the diameter of the part 1, which will be deformed in the caulking aria.

- ØDp2 - diameter of the part 2, which is going to be assembled in the caulking aria.

- ØDc - tool diameter.

- $r$ - constructive parameter of part 1 .

- A1 - clearance angle of the tool.

- A2 - rank angle of the tool.

All this parameters are independent one from each other and in this way they have a big influence on the caulking process.

Together with the geometric parameters, the caulking process demands also a list of technological parameters:

- V- The speed (velocity) of the caulking process.

- T - Tool pressing time.

- F - Caulking force.

- The accuracy of the devices: perpendicularity; linearity etc.

After the caulking process is performed, there are several output parameters which occurs.

The geometrical parameters can be seen in the following picture (Fig 6): 


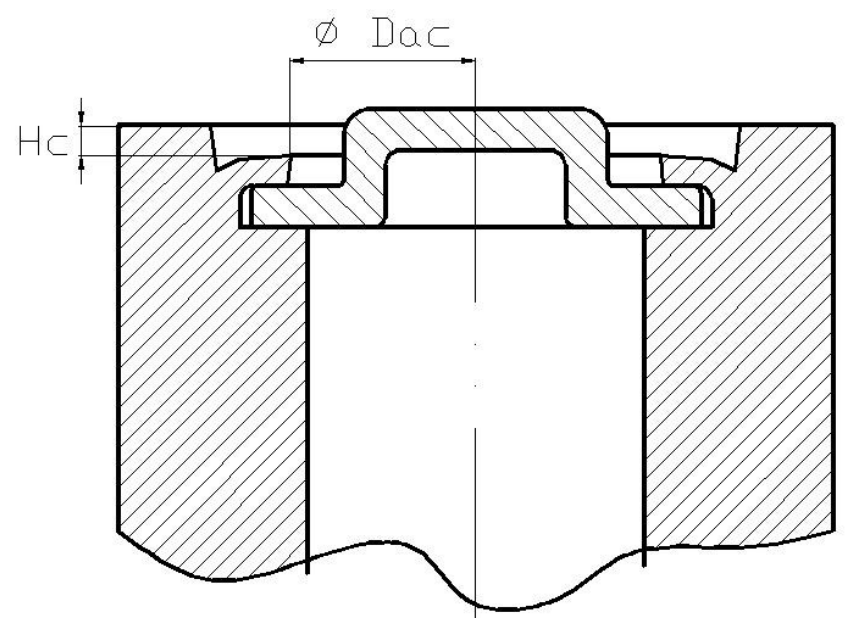

Fig. 6. Geometrical parameters after the caulking process

The output geometrical parameters are:

- Ø Dac - the actual diameter of the caulked material.

- Hc - the height of the caulked material which covers the second part.

Together with the output geometrical parameters, the caulking process includes also a list of output technological parameters:

- Sp_gas - the speed of the decreasing pressure inside the caulked assembly - gas conditions.

- Sp_liq - the speed of the decreasing pressure inside the caulked assembly - liquid conditions.

- Bp - the limit of the burst pressure.

Table 1. Caulking parameters

\begin{tabular}{|c|c|c|c|}
\hline \multicolumn{2}{|c|}{ Input Parameters } & \multicolumn{2}{c|}{ Output parameters } \\
\hline Name & Measuring unit & Name & Measuring unit \\
\hline $\mathrm{H}$ & {$[\mathrm{mm}]$} & $\varnothing \mathrm{Dac}$ & {$[\mathrm{mm}]$} \\
\hline$\varnothing \mathrm{Dp} 1$ & {$[\mathrm{~mm}]$} & $\mathrm{Hc}$ & {$[\mathrm{mm}]$} \\
\hline$\varnothing \mathrm{Dp} 2$ & {$[\mathrm{~mm}]$} & Sp_gas & Mbar*1/s \\
\hline$\varnothing \mathrm{Dc}$ & {$[\mathrm{mm}]$} & Sp_liq & Bar/s \\
\hline $\mathrm{r}$ & {$[\mathrm{mm}]$} & $\mathrm{Bp}$ & Bar \\
\hline $\mathrm{A} 1$ & {$\left[{ }^{\circ}\right]$} & & \\
\hline $\mathrm{A} 2$ & {$\left[{ }^{\circ}\right]$} & & \\
\hline $\mathrm{V}$ & {$[\mathrm{m} / \mathrm{s}]$} & & \\
\hline $\mathrm{T}$ & {$[\mathrm{s}]$} & & \\
\hline $\mathrm{F}$ & {$[\mathrm{KN}]$} & & \\
\hline
\end{tabular}

The definition of all the caulking parameters (Table 1.) allows us to perform a systematic analysis of the process. 


\section{The functional analysis of the caulked assembly}

Starting from the requirements presented before, we aim to establish the assembly functions (Table 2.) and then to determine which ones are more important. This analysis allows us to design the research in order to optimize the caulked assembly.

Table 2. The functions of the caulked assembly

\begin{tabular}{|l|l|}
\hline \multicolumn{1}{|c|}{ Requirement } & \multicolumn{1}{c|}{ Function } \\
\hline $\begin{array}{l}\text { Precise geometrical parameters and high surface quality of the } \\
\text { deformed volume of material }\end{array}$ & Precision \\
\hline An adequate stress state along the entire caulking length & Resistance \\
\hline Assembly must withstand to fatigue. & Reliability \\
\hline The assembling must have very good tightness & Tightness \\
\hline Low cost of the operation & Cost \\
\hline
\end{tabular}

The ranking of the functions is evaluated taking into consideration the importance of each one in the life-cycle of the final assembled product (Product lifecycle methodology).

The adopted method for this evaluation is "the triple cross method" (Fig 7).

\begin{tabular}{|c|c|c|c|c|c|c|c|c|c|c|}
\hline & F2 & F3 & F4 & F5 & s & R & & P [\%] & & precicion \\
\hline F1 & 1 & 1 & 1 & 2 & 5 & 0.125 & F1 & 12.5 & F2 & -resistance \\
\hline & F2 & 2 & 2 & 3 & 10 & 0.25 & F2 & 25 & F3 & -reliability \\
\hline & & F3 & 2 & 3 & 10 & 0.25 & F3 & 25 & F4 & -tightness \\
\hline & & & F4 & 3 & 10 & 0.25 & F4 & 25 & F5 & -cost \\
\hline & & & & F5 & 5 & 0.125 & F5 & 12.5 & & \\
\hline & & & & & & & & & \multicolumn{2}{|c|}{ Importance factor } \\
\hline & & & & & & & & & & \\
\hline
\end{tabular}

Fig. 7. Ranking functions; triple cross - method

Each function is compared with another one and receives some points in the following way:

- If a function is more important than another one it receives 3 points.

- If a function has the same importance with another one it receives 2 points.

- If a function is less important in comparison with another one it receives 1 point.

The ranking shows that the tightness, resistance and the reliability are the most significant functions for the caulked assembly.

\section{The actual methods used for the evaluation of the caulked assemblies}

As it was mentioned before, the sealing between the two parts which had suffered the caulking process is one of the most important requirements. Due to the fact that caulking process is very often used in brake systems from the automotive field, a simple inadvertence during the caulking process can lead to important damages to the functionality of the final product (Fig. 8). 


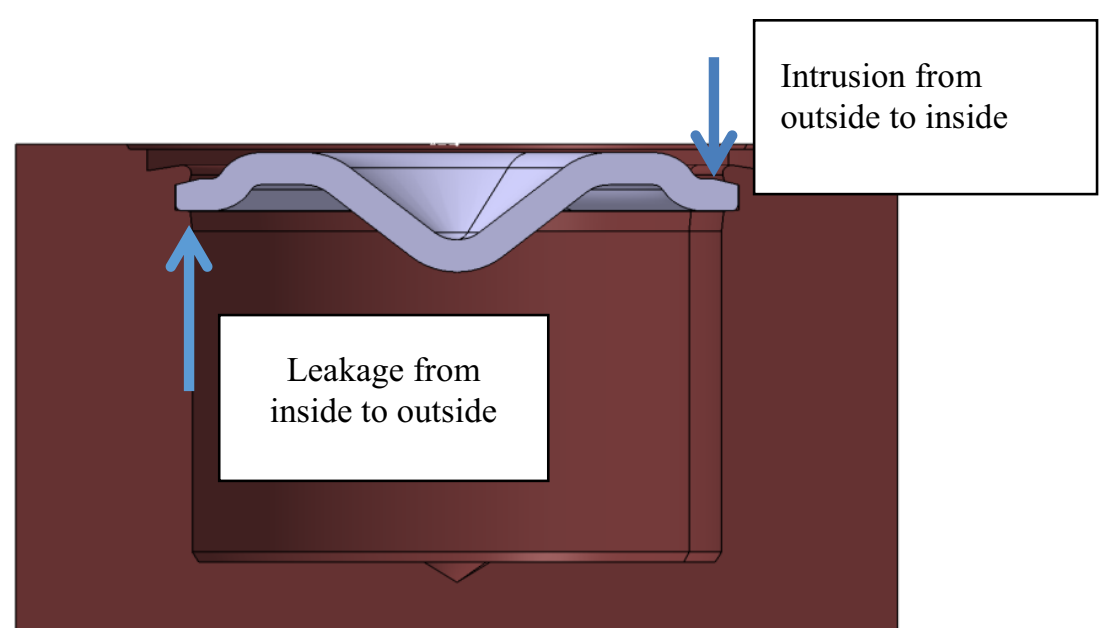

Fig. 8. Possible sealing problems at caulked assembly

There are two possible problems if the sealing was not performed in good conditions. A first one is the possible intrusion of gas or liquid from outside to inside the caulked assembly. The second one is a possible leakage of gas or liquid from inside to outside the caulking assembly.

In the caulked assembly the tightness is checked to assure that there is no leakage between the inside of the assembly and the outside.

Checking out the tightness of a product obtained after a caulking process implies the measurement of a fluid flow coming out of a defect or entering through it. Leak detection is a non-destructive test performed to verify the accordance of products and components with the prescribed specifications, by using techniques, which do not damage their characteristics or performances. The leak test is continuously implemented in a production process, to check the agreement of the goods to the tightness requirements.

Considering the functionality of the final product obtained after caulking process, the tightness requirements can be checked with liquids or gases. Some methods are presented next.

\subsection{Method for testing the caulked assembly tightness using helium}

The testing of a non-removable assembly is done using a special instrument which is based on the detection of helium.

The working principle of the helium leakage test device is as it follows. The caulking assembly is connected to the test device. Everything that exists inside the assembly is emptied using a vacuum pump.

Helium is flushed towards the caulked area to determine tightness. Helium can penetrate into very small holes and may reveal the quality of the caulked assembly (Fig. 9). 


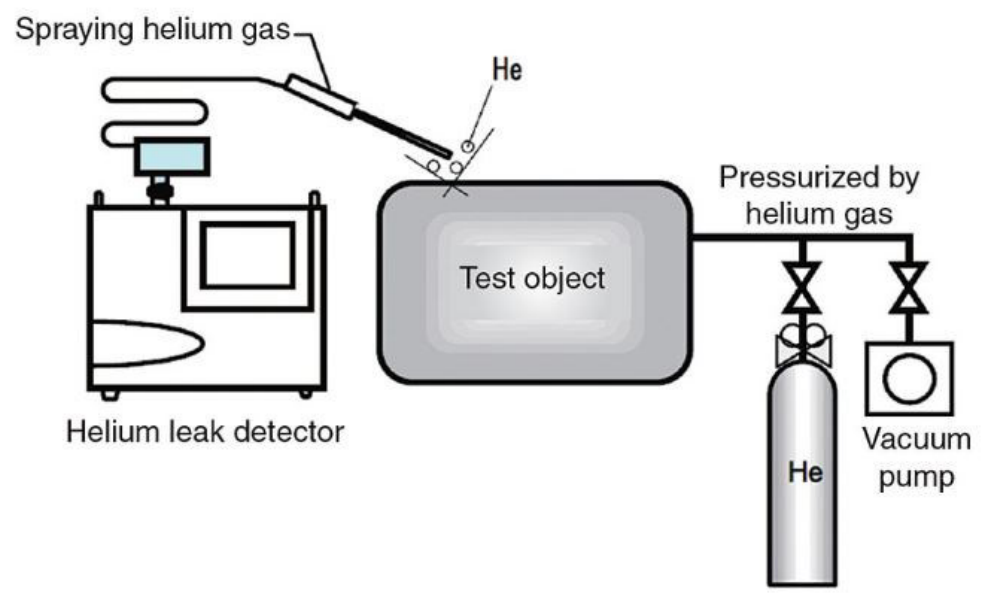

Fig 9. Helium leakage method

In normal conditions (proper conditions for the functionality of the final product) the left side of each curve must be in the right side of the pressure of 1 bar.

Due to the fact that the caulking process was not performed in good conditions there was a leakage of the gas from inside the assembly to outside and in this case the functional curve (coloured with blue) was moved to the right side of the pressure of 1 bar. In these conditions the assembled product will not be able to perform its normal functionality.

The red curve from the picture shows how the functionality of the product must look when the caulking process is performed in good conditions.

The picture with two curves presents how important is to perform the caulking process in good conditions. Even if everything seems to be ok from the visual point of view, a simple pore in the caulking process can lead to clear damage of the final product.

In the following picture, examples of good and bad tightness can be seen, measured with the equipment presented before (Fig. 10).

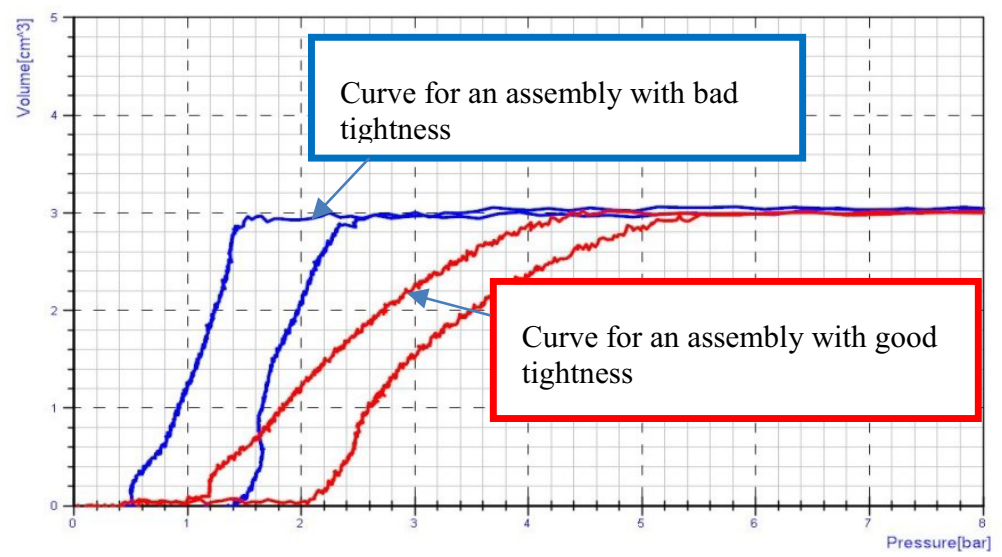

Fig. 10. Tightness evaluation using gas pressure 


\subsection{Method for testing the caulked assembly tightness using hydraulic pressure}

Another method which can be used to check the tightness of the caulking process is the hydraulic tightness of the assembly.

This method consists of holding up a certain value of a pressure inside the caulking assembly and check if there is a pressure drop in a certain amount of time. This type of tightness test is used for assemblies which are supposed to run at low pressures.

In figure 11, the result of a hydraulic test (done after a caulking process) is presented. The parameters used for the test were a holding pressure of 22 bars and a holding time of 600 seconds. The graph shows that there was no pressure drop during the entire test.

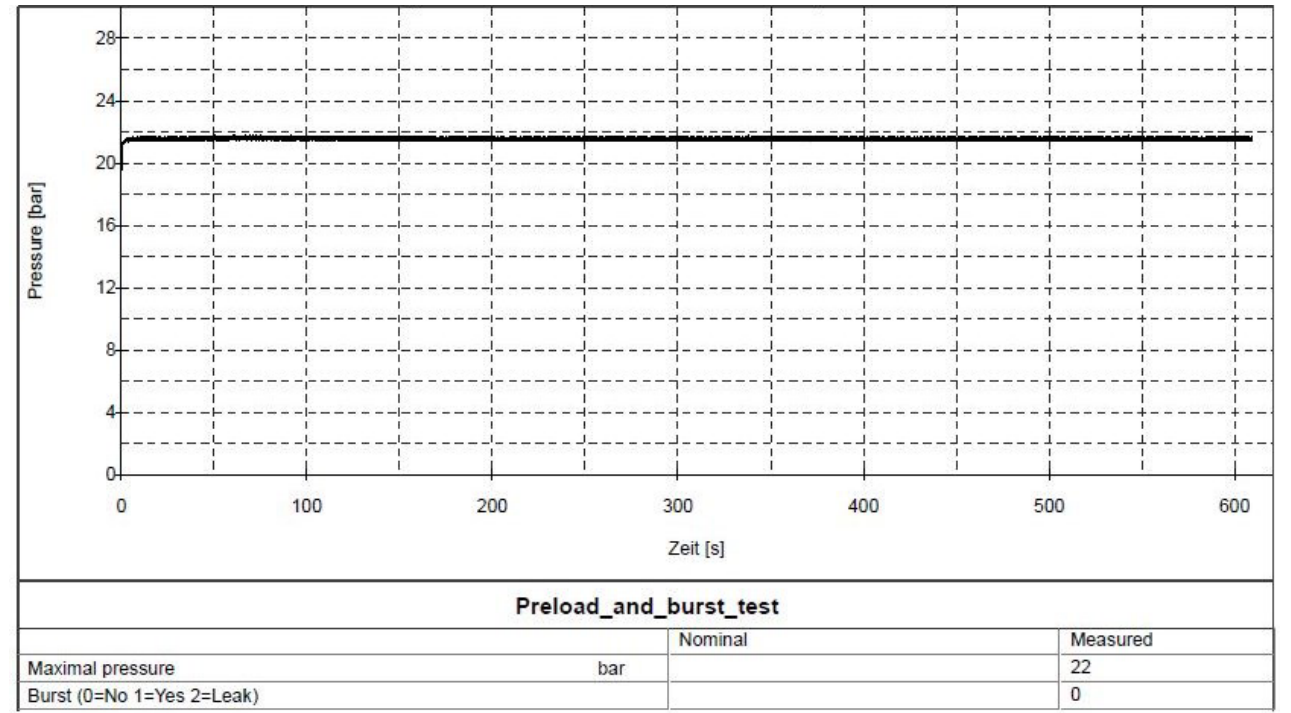

Fig. 11. Hydraulic tightness testing

\subsection{Method for testing the burst pressure}

There are cases when the caulked assembly must stand against big values of pressure. The best method to test if a caulked unit can meet the expectations of these kinds of big values is the burst pressure test.

Burst pressure tests are performed on dedicated test benches which are able to provide very big values of pressure inside the caulked assembly (test benches can go to values of 1500 bars - Fig 12). 




Fig. 12. Burst pressure test bench



Fig. 13. Assembly failed at burst pressure test

A specific problem with the burst pressure value can be seen in the following picture (Fig 13): The assembly didn't resist to the testing pressure. In figure 14, the recording of a failed test is presented. After 20 seconds, the assembly failed.

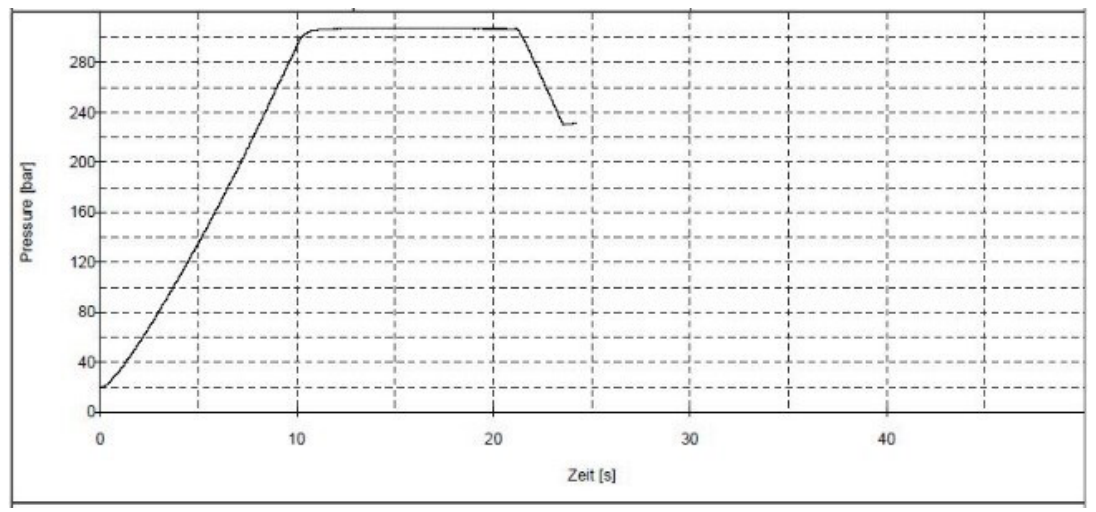

Fig. 14. Recording of a failed burst pressure test 


\subsection{Measuring the geometrical parameters of the caulked area}

The amount of material which covers one of the parts and in this way creates the caulked assembly is also very important for the success of the process. This amount of material can be measured in many ways. The simplest one is the measurement of the height of the deformed material (Fig 15).



Fig. 15. Height of the deformed material at caulking process

It is highly important that this height of deformed material to be constant on all over the assembled area. A single zone where the height is smaller can lead directly to problems such as air leakage or low burst pressure value.

\subsection{Comparative analysis of the testing methods for the caulked assembly}

By analysing the testing methods presented before, it was possible to underline the input and the output data for each of them. The synthesis of this information is presented in table 3 .

Table 3. Comparative analysis of the measurement methods used for the verification of the caulked assembly

\begin{tabular}{|c|c|c|}
\hline Measurement methods & Input Parameters & Output Parameters \\
\hline $\begin{array}{l}\text { Measurement of caulked } \\
\text { assembly tightness using } \\
\text { helium }\end{array}$ & $\begin{array}{ll}\text { - } & \text { ØDc; } \\
\text { - } & \mathrm{H} ; \\
\text { - } & \mathrm{T} ; \\
\text { - } & \mathrm{F} ; \\
\text { - } & \text { ØDp1; } \\
\text { - } & \text { ØDp2. }\end{array}$ & $\begin{array}{ll}- & \mathrm{Hc} \\
- & \varnothing \mathrm{Dac} ; \\
- & \text { Sp gas. }\end{array}$ \\
\hline $\begin{array}{l}\text { Measurement of caulked } \\
\text { assembly tightness using } \\
\text { hydraulic pressure }\end{array}$ & $\begin{array}{ll}\text { - } & \varnothing \mathrm{Dp} 1 ; \\
\text { - } & \varnothing \mathrm{Dp} 2 ; \\
\text { - } & \varnothing \mathrm{Dc} ; \\
\text { - } & \mathrm{H} ; \\
\text { - } & \mathrm{T} ; \\
\text { - } & \mathrm{F}\end{array}$ & $\begin{array}{ll}- & \mathrm{Hc} ; \\
- & \varnothing \mathrm{Dac} ; \\
- & \text { Sp liq. }\end{array}$ \\
\hline $\begin{array}{l}\text { Measurement of burst } \\
\text { pressure limit }\end{array}$ & $\begin{array}{ll}\text { - } & \varnothing \mathrm{Dp} 1 ; \\
\text { - } & \varnothing \mathrm{Dp} 2 ; \\
\text { - } & \varnothing \mathrm{\varnothing D} ; \\
\text { - } & \mathrm{H} ; \\
\text { - } & \mathrm{A} 1 ; \\
\text { - } & \mathrm{A} 2 ; \\
\text { - } & \mathrm{r} ; \\
\text { - } & \mathrm{T} ; \\
\text { - } & \mathrm{S} ; \\
\text { - } & \mathrm{F}\end{array}$ & $\begin{array}{ll}- & \mathrm{Hc} ; \\
- & \varnothing \mathrm{Dac} ; \\
- & \mathrm{Bp}\end{array}$ \\
\hline
\end{tabular}


The presented methods analyse the tightness and the resistance of the caulked assemblies. None of the methods analyse the reliability of the caulked assembly. Therefore there is a need to develop a new test bench which will be able to test this function of the product.

\section{Experimental researches}

The analysis done before was applied to an experimental research. The aim of the research was to test the validity of the analysis made in this work and to develop a coherent methodology for testing the caulked assemblies. The input parameters are presented in table 4 .

Table 4. Input parameter for the experimental research

\begin{tabular}{|c|c|c|}
\hline Name & Values & Measuring unit \\
\hline $\mathrm{H}$ & 2.65 & {$[\mathrm{~mm}]$} \\
\hline$\varnothing D \mathrm{Dp} 1$ & 25.63 & {$[\mathrm{~mm}]$} \\
\hline$\varnothing \mathrm{Dp} 2$ & 25.48 & {$[\mathrm{~mm}]$} \\
\hline$\varnothing \mathrm{Dc}$ & 2.85 & {$[\mathrm{~mm}]$} \\
\hline $\mathrm{r}$ & 0.82 & {$[\mathrm{~mm}]$} \\
\hline $\mathrm{F}$ & 76 & {$[\mathrm{KN}]$} \\
\hline
\end{tabular}

The visual inspection reveals a good shape of the caulked assembly.

At the testing of the tightness using helium, the speed of the decreasing pressure inside the caulked assembly - gas conditions. (Sp gas) - result $7.8 * 10 \mathrm{E}-10 \mathrm{mbar} * 1 / \mathrm{s}$. As a result, the assembly tightness function regarding gas pressure is assured.

At the testing of the tightness using- liquid (Sp liq) - the assembly was tested under a pressure of 20 bar for a time of 20 minutes - without any leakage drop. The assembly tightness function regarding liquid is assured.

The test for burst pressure (Bp limit test) - was done for the burst pressure limit and the value is ca. 363 bar. The assembly is assured from the burst limit point of view.

The experiment reveals the fact that for the geometrical parameters presented in the table all the requirements for the final caulked product are respected.

Experimental research revealed the algorithm necessary to fully evaluate a caulked assembly.

\section{Methodology for testing the caulked assemblies}

The functional analysis done before revealed that tightness, resistance and reliability are the most significant functions for the caulked assembly. Actual testing methods are focused on tightness and on resistance. The logical order of doing these tests is presented in figure 16. First the gas pressure test is done. If the assembly pass the test, then the liquid pressure test is done. If the assembly passes this test too, than the burst pressure test is done. 




Fig 16. Algorithm of testing caulked assemblies

The study shows that the reliability function is not analysed. There is a need of developing a new stand for reliability testing. 


\section{Conclusion}

The paper highlights the caulking process as a systemic process. The input data and the output data of the process were presented together with the methods of analysing the performance of the caulking assembly.

The actual knowledge and test equipment allowed us to perform an experimental research which reveals the validity of the measurements methods.

The performed analyse and the presented algorithm allows a complete and complex assessment of the performances regarding the caulking process.

In the future we propose to study the optimization of the input parameters in order to obtain precise assemblies for different materials and also for different dimensions of the parts.

This methodology can be used to achieve optimization of the process in order to process parts of various materials and also with different dimensions.

\section{References}

1. B.-S. Sin, K.-H. Lee, The Scientific World J., Article ID: 971679 (2014)

2. J. Park, J.Park, S. Choi, K. Na, Y. Kim, J. Mat. Processing Tech., 198, 471, (2006)

3. J. Beck, R. Ziegler, N. Schonheit, Nuclear Eng. And Design, 263, 179 (2013)

4. A. Celcatelli, M. Bergoglio, D. Mari, Vacuum, 81, 1538 (2007)

5. Y. Gorash, W. Dempster, W. D. Nicholls, R. Hamilton, A. A. Anwar, J.of Loss Prevention in the Process Ind., 43, 61 (2016) 